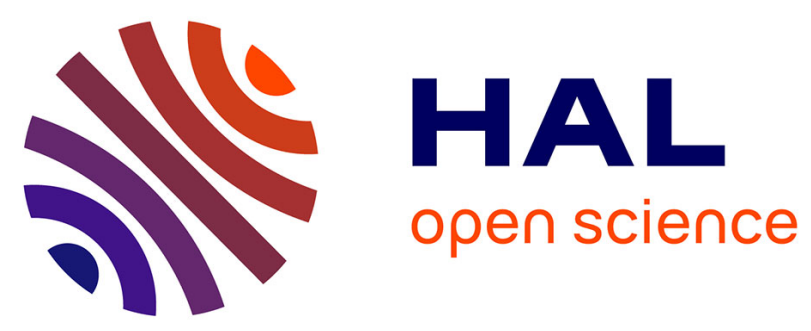

\title{
CALCULATION OF CONVERSION COEFFICIENTS FOR ANTHROPOMORPHIC PHANTOMS FOR CRITICALITY DOSIMETRY
}

Marie Anne Chevallier, Jean-Baptiste Pontier, Héloïse Morin, Matthieu Duluc, Stephane Evo, Eric Letang, Francois Trompier

\section{To cite this version:}

Marie Anne Chevallier, Jean-Baptiste Pontier, Héloïse Morin, Matthieu Duluc, Stephane Evo, et al.. CALCULATION OF CONVERSION COEFFICIENTS FOR ANTHROPOMORPHIC PHANTOMS FOR CRITICALITY DOSIMETRY. Radiation Protection Dosimetry, 2020, 191 (1), pp.9-24. 10.1093/rpd/ncaa123 . hal-03098807

\section{HAL Id: hal-03098807 https://hal.science/hal-03098807}

Submitted on 5 Jan 2021

HAL is a multi-disciplinary open access archive for the deposit and dissemination of scientific research documents, whether they are published or not. The documents may come from teaching and research institutions in France or abroad, or from public or private research centers.
L'archive ouverte pluridisciplinaire HAL, est destinée au dépôt et à la diffusion de documents scientifiques de niveau recherche, publiés ou non, émanant des établissements d'enseignement et de recherche français ou étrangers, des laboratoires publics ou privés. 


\title{
CALCULATION OF CONVERSION COEFFICIENTS FOR VOXELIZED PHANTOMS FOR CRITICALITY ACCIDENT DOSIMETRY
}

\author{
M.-A. Chevallier ${ }^{1}$, J.-B. Pontier ${ }^{2}$, H. Morin ${ }^{3}$, M. Duluc ${ }^{1}$, S. Evo ${ }^{1}$, E. Letang ${ }^{1}$ and F. Trompier ${ }^{1, *}$ \\ ${ }^{1}$ Institut de Radioprotection et de Sûreté Nucléaire (IRSN), BP 17, 31 avenue de la Division Leclerc, 92260 \\ Fontenay-aux-Roses, France \\ ${ }^{2}$ CEA, Centre de Saclay, 91190 Gif-sur-Yvette \\ ${ }^{3}$ ÆRGON, 16 rue Jean-Jacques Rousseau, 92130 Issy-les-Moulineaux
}

*Corresponding author: francois.trompier@irsn.fr

Received month date year, amended month date year, accepted month date year

\begin{abstract}
In the event of a criticality accident, not only the maximal doses received by the victims must be determined butit is also crucial to evaluate the doses to the different organs. With a neutron component, morphology is a key parameter in the organ dose calculation. As the simulation tools can be time consuming to proceed, especially if morphology is taken into account, for all the victims, it $m$ ay be very useful to $h$ ave a database of conversion coefficients that allow to obtain the organ doses from the dose measured in the dosemeter for different kinds of morphology. In this paper, we present a stu dy performed to evaluate such conve rsion coefficients u sing voxelized anthropomorphic ph antoms. These coefficie nts take into account two crucial parameters having an impact on the dose at the organs: the orientation of the victim in the radiation field and the morphology, that is to say the body mass index of the different victims.
\end{abstract}

\section{INTRODUCTION}

A criticality accident is a very specific type of accident from the dosimetry point of view and the medical management, due to the mixed gamma and neutron fields and due to dose ranges which could be out of the range of classical individual dosimetry systems. An overview of measurements techniques and criticality accident dosemeter designs is provide in an IAEA technical report as well as the objectives of such dosimetry [1]. The maximal neutron and gamma doses in the individual must be determined and separately (because of different biological effect of neutrons and gammas) as well as other information such as the orientation of the victim in the radiation field and some information on incident neutron spectrum. Nevertheless, due the strong dose gradient in the body with neutrons, the sole information on the maximal doses given by the individual dosemeter would be meaningless from a medical point of view. The evaluation of absorbed dose in organs is here crucial, even more than in the case of accident with a gammarays sources for example. Moreover, as for the maximal doses, it is also important to segregate the neutron and gamma dose components doses in organs.
The doses measured by the individual dosemeters provide in the best case only an estimation of the maximal doses received by the victim and only if the individual is exposed face-on to the source. In all the other circumstances, a correction factor to take into account the orientation on dosemeter response has to be applied on the dosemeter's reading. This correction factor can be estimated only if the orientation of the individual in the radiation field is known. Orientation is usually determined with a "criticality belt" composed with a minimum of 4 dosimetric lockets dispatched around a belt or by hair and hairs activation analysis when possible. The four dosimetric pellets could be situated for instance like this: one the front side, on the left side, one on the right side and the latest on the back of the worker, but six pellets placed every $60^{\circ}$ being optimum. The relative activation of the different pellets enables to have a better idea of the incidence of the neutron radiation field during the accident.

For an acute irradiation, in addition of maximal doses, the dose distribution within the human organism is also needed as it is a key data to rapidly define the best therapeutic strategy. However, this last aspect in not up to now taken into account in criticality accident procedures and dosimetry methods. 
Different strategies could be adopted to have the dose at the organs, but none are ideal and hardly usable in emergency situation. First of all, it must be underlined that a first needed input data is the neutron spectrum of the accident, whatever is the chosen strategy. This is one of the main difficulty. Information on neutron spectra can be obtained by different means: either simulations if the source term is known, or experimentally using an area neutron spectrometer (e.g. SNAC2) [1] or a system as the Nuclear Accident Dosemeter (NAD) with advanced design. All these possibilities have some limitations: evaluation of source term is a time consuming action, area dosemeter can be at distance from the exposed individuals and maybe not relevant, NAD are perturbed by the body of the wearer and will not work for PA or even LAT orientations. Anyway, once having the neutron spectrum one can choose between:

A complete and detailed simulation created ex nihilo from the collected information on accident site. Voxelized phantom could then be built from the analysis of CT or MRI whole body imaging files and therefore allows very accurate and detailed description of the individual morphology. It is obviously a time consuming actions, especially if several individuals are involved. So this strategy will be quite a long process and is not compatible with exigencies of the medical management. As a matter of fact, we would like to remind that a first dose estimation is requested in a delay of 24 hours, with a refined estimation within one week.

- The second strategy consists in a pragmatic method: once the orientation, the maximal dose determined and neutron energy spectrum determined, then the dose distribution within the individual can be estimated using as proposed here precalculated conversion factors. These conversion factors are defined as the ratio of the maximal doses estimated with the NAD and the doses at the organ of interest, for a given neutron energy or a neutron spectrum. Secondary gamma dose from thermal neutron reactions on hydrogen and fast neutron dose being estimated separately. The whole body dose estimated with ${ }^{24} \mathrm{Na}$ activity in blood sample analyzed by gamma spectrometry or whole body counting could be also used as input data for organ dose calculation. The calculation of the conversion coefficients are performed once, far before the potential criticality accident. On the day a criticality accident occurs, it will then be easy to convolute the conversion factors as a function of the neutron energy with the neutron spectrum of this specific criticality accident, in order to assess a first estimation of the doses at the organs.

In the second strategy, the question is raised of the choice of the phantom to use to calculate the conversion coefficients. Indeed, more than with photons, due to their interaction process in tissue, neutrons dose gradients in the body is extremely important. For a standard morphology as defined in the ICRP for example, in AP or PA irradiation, the ratio between the dose at the entrance and at the exit can reach a factor 20. In this paper, we demonstrate the very strong influence of the morphology on the organ doses for neutron irradiation. A same entrance dose would give very different organ dose for individuals with different morphology. Therefore, it is not recommended to use a standard numerical phantom to assess organ doses of exposed individuals. Considering neutrons interactions specificity and the accuracy needed in case of acute exposure with expected deterministic effect, the recommended solution is rather to build a numerical phantom based on the morphology of each exposed individual using for example voxelized phantom. Nevertheless, this approach is time consuming, especially if several individuals are involved and therefore not compatible with the short delay imparted. That's why, we are proposing for a first and rapid dose estimation as it is mandatory, a web tool based on a database of conversion coefficients from dose in NAD to dose in organs for different geometries and energies, for photon and neutron and with a series of voxelized phantom with various types of morphology as much as possible covering the mass body index range found in population. We are aware that this first dose estimation could be also affected by morphology differences between the individual and the closest morphology found in the database, but our data show that would be far better than using a standard phantom. Moreover, the uncertainty accepted for this first evaluation usually done within 24 hours is higher (50\% in France) than the one for the refined dose evaluation done in second time (25\% in France). To sum up, the calculated conversion coefficients that fill the database used for the web tool are defined by the ratio of the doses received in the dosemeter and the dose received in a specific organ for a given configuration of irradiation, a given morphology and a given particle energy or spectra.

The upcoming web tool is based on the DIOMEDE tool [2]. Initially, the DIOMEDE tool aims to provide rapid dose estimation for radiological accident, not only restricted to criticality accident. The coefficients were calculated as the ratio of the dose in an individual dosemeter, or in a biological tissue analyzed by EPR spectrometry (tooth enamel and dentin, bone), or 
personal items (medicine tablets, candies...) analyzed either by EPR spectrometry or luminescence to the absorbed doses in human body organs. As DIOMEDE aims to cover most of accident situations, various geometries were considered in addition of ISO standard geometries, such as a contaminated floor or a source located in the clothes' pockets. The choice of the geometries considered in this database was based on the most encountered scenarios of radiological accidents. Even if IRSN has been involved in numerous expertise for medical management of highly irradiated individuals, the DIOMEDE tools was actually never used. Actually, the progress in the MC simulation, making it faster and easier makes the initial concept of DIOMEDE obsolete, at least for the classical accident scenarios. Such approach have been recently reconsidered for triage in case of large scale accident. However, in the process of renewing the doctrine and tools used specifically for the management of criticality accident from the medical point of view, it came out, that the concept of DIOMEDE could be useful in this specific field. The dose assessment in that field could not only be limited to the dose evaluation based on NAD analysis. As for all other accident typologies, the dose estimation in organs of interest is a crucial aspect and actually even more crucial considering the specificity of neutrons evocated above.

Nevertheless, in the DIOMEDE tool, coefficients had been initially calculated with a standard mathematical phantom (MIRD) that really limits the usefulness of such tool for criticality accident, due to the lack of representability of a standard phantom compared to real body morphology and especially considering neutron irradiation. With new possibilities offered by voxelized phantom technology, we have considered that DIOMEDE could be therefore updated with new sets of coefficients. We have considered that this updated tool could be very pertinent in case of criticality accident and fill a gap in the tools available for criticality dosimetry and accident management. A new set of coefficients have been calculated using a library of voxel phantoms [3]. The idea being to have a sufficiently large library of voxelized phantoms in order to find for every individual a phantom morphology enough close to the individual morphology to provide a sufficiently accurate dose estimation. Up to now, we did not define the number of phantoms needed and the expected variation in dose assessment. The work presented here aims to demonstrate the necessity of such tool by studying the influence of the body morphology on dose in organs for different geometry of exposure with neutrons. Geometries of calculation were presented here for this demonstration to AP, PA, LAT configurations. In the next step of this work, more realistic geometries have to be defined, based on the study of criticality accidents.
Moreover, such methodology lays on the assumption that the neutron spectrum is known. In facility with a risk of criticality accident, some system can provide very rapidly some information on the neutron spectrum. Actually, two solutions are used and none of these are perfect solution. Both used activation foils. First one consists in area neutron spectrometers (based on activation foil) placed at strategic locations in the facilities. The neutron spectra measured to the closest position is used to correct dosimeter reading and to provide a first rapid estimation usually within the first 24 hours. This data can be sued in second time to validate MC simulation. Main drawbacks are the position close to wall and sometimes not that close to individuals. Second option is to have an advanced NAD with multi foils in order to provide an estimation of the neutron spectra. Main drawbacks are the albedo effects and the impossibility to use these data for PA configuration. Normally, a first idea of the spectra can be obtained in very short delay that could be sufficient for the first estimation that is asked with $50 \%$ uncertainty. In the proposed DIOMEDE tool, some typical neutron spectra will be proposed, such as those published in the IAEA neutron spectra compendium or more recent obtained with metallic core or with solution at different distance. Spectra from solution reactor have a much more important thermal neutron component the metallic one and these component is known to increase with distance. It will be also to upload a spectrum, to calculate for a given morphology and orientation the dose coefficients to organs.

The DIOMEDE web tool aim to be freely available. The web tool could be feed by anyone willing to participate to this initiative. This initiative has been endorsed by EURADOS WG10 and it is planned that, in the future, an evaluation committee formed by EURADOS members will be in charge of the validation of coefficients submitted to be implemented in the DIOMEDE tool.

\section{MATERIAL AND METHODS}

The aim of the study is to calculate for different body morphologies a ratio between the dose received by specific organs and the neutron kerma in tissue that should be estimated with the NAD, for several incident neutron energies. These two quantities are calculated using Monte Carlo simulations. We did the assumption that the neutron kerma in tissue estimated by simulations would correspond to what the dosemeter would measure when a criticality accident would occur, because the NAD used at IRSN is designed and calibrated to estimate neutron kerma in tissue that is a good approximation of the maximal neutron doses in

\footnotetext{
*Corresponding author: francois.trompier@irsn.fr
} 
the body [1].

\section{Anthropomorphic phantoms}

To calculate such ratio, in attempt to demonstrate the usefulness of such approach, four male anthrop omorphic phantoms M 1A, M 1C, M 1E and M1I were used with different corpulences: height of $176 \mathrm{~cm}$, Body Mass Index of 16.5, 23.3, 31.2 and 45.2 respectively (cf. Figure 1). These phantoms come from the commercial database CAESAR and they were defined using 3D medical imaging [3]. The M1C phantom matches, in terms of height and weight, the reference phantom of the ICRP 110 [5]. The difference in terms of weights of the different considered organs is given in the reference [3]: the relative masse difference from the M1C phantom to the one from ICRP report is about $-0.52 \%$ for the liver, $+1.34 \%$ for the stomach wall, $-0.03 \%$ for the prostate for instance. However, what is just as important as the mass and density of the tissue of each organs is the difference of the position of the organ itself in the body (cf. discussion later in the paper).

The phantoms M1A and M1I represent the two opposing extremes in terms of weight that can be found among the usual morphologies.

The conversion coefficients were calculated for 13 organs: colon, left and right lungs, stomach, left and right testicles, liver, heart, left and right kidneys, bladder, prostate and small intestine.

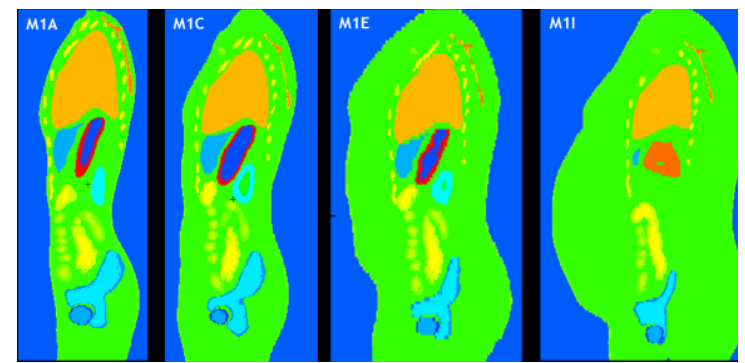

Figure 1: Sagittal sections of the studied voxelized phantoms M1A, M1C, M1E and M1I.

\section{Calculated quantities}

The different calculated terms are the following:

- The neutron fluence and the neutron kerma in tissue,

- The "neutron dose", corresponding to the kinetic energy given by collision to the atoms composing the media (tissue),

- The "secondary photon dose", delivered by the secondary charged particles initiated by the photons interaction coming mainly from the $(\mathrm{n}, \gamma)$ reaction on hydrogen.
The sum of the last two doses gives the total absorbed dose at one given organ. In this paper, we only report data for the conversion coefficient that is defined as the ratio of the total dose received by each organ of the victim and the neutron kerma in tissue that could be ideally measured by the NAD for a given configuration of irradiation. The choice to present only the coefficients with the total absorbed doses in organ was done to be able to compare our data with those for ICRP. As the "neutron dose" from recoil nuclei and the secondary gamma dose are calculated separately, it is possible therefore to define some coefficients for these two quantities.

Two spheres of $1 \mathrm{~cm}$ of diameter are positioned around the phantom. The first one represents the NAD position and is then fixed at the front of the trunk for a given corpulence at the surface of the phantom, whatever the neutron incidence is. The second sphere is positioned also at the surface of the phantom but in the axis of the incident neutrons to calculate the maximal dose at the surface of the phantom whatever the phantom orientation in the field is.

\section{Simulation tools}

The calculations were performed using MCNP code version MCNPX 2.6, with the nuclear libraries ENDF/B-VI (.66c format) for the neutrons and ENDF/B-VI.8 (.04p format) for the photons [4].

\section{MCNP responses: used tallies}

In order to calculate the conversion coefficients thanks to MCNP code, several tallies were used:

The neutron kerma in tissue is calculated by a F4:n tally inside the sphere of $1 \mathrm{~cm}$ of diameter, filled in air and placed front of the trunk. The sphere representing the dosemeter is situated at the chest level: for the MIC phantom, the position is $\mathrm{X}=44 \mathrm{~cm}, \mathrm{Y}=5.4 \mathrm{~cm}$ and $\mathrm{Z}=132 \mathrm{~cm}$.

This tally is an estimator of the neutron fluence inside this volume. It is then multiplied by the fluence-totissue-kerma-in-air conversion coefficients issued from the IAEA report [1]:

$$
\begin{aligned}
& k(E)=3.3 \times \frac{10^{-5}}{\sqrt{E}}+78 \times E^{0.96} \\
& \text { for } 10^{-8} \leq E \leq 0.035 \mathrm{MeV} \\
& k(E)=22.2 \times E^{0.074-0.05 \ln (E)}+5-\frac{5}{\left(1+\left(\frac{E}{13}\right)^{10}\right)} \\
& \text { for } 0.035 \leq E \leq 15 \mathrm{MeV}
\end{aligned}
$$


The dose due to the heavy charged particles called "neutron dose" in this paper is estimated using a type *F6 :n.

Concerning the dose induced by the $(\mathrm{n}, \gamma)$ reaction and assimilated to the "secondary photon dose", a *F6:e tally is used. Indeed, the volume of the cells at which the tally is calculated is very small and it that case, the MCNP documentation recommends to use the *F6:e instead of *F6:p. Moreover it was checked that using the NPE mode, +F6 tally's results is equal to the sum of the results of the tallies F6:n and F6:e.

\section{The neutron source}

For all the configurations, the neutron source is plane and rectangular, with a variable size as a function of the phantom's model. Indeed, as we focused on the ratio of the dose measured in the dosemeter and the dose at the organ, we could adapt the geometry of the neutron source in order to optimize the calculation time of the simulations.

The neutrons are emitted in one direction only, perpendicular to the source surface and directed to the phantom. The number of simulated neutron histories is enough to ensure a statistical uncertainty of the calculation of the neutron kerma in tissue below $1.5 \%$.

The source emits mono-energetic neutrons at the following energies: $10^{-9}, 10^{-8}, 10^{-7}, 10^{-6}, 10^{-5}, 10^{-4}, 10^{-3}$, $10^{-2}, 0.1,1,5,10$ and $20 \mathrm{MeV}$. A conversion function can be built using the conversion coefficients obtained with these 13 neutron energies in order to adapt the result to any neutron spectra of any criticality facility.

Four orientations are studied in order to estimate the effects of the irradiation angle on the received dose to the organs: $0^{\circ}(\mathrm{AP}), 90^{\circ}$ (RLAT), $180^{\circ}(\mathrm{PA})$ and $270^{\circ}$ (LLAT). The figure 2 shows the different possibilities of orientation of the neutron source. The NAD is always placed at front face of the phantom, at the chest level. Notice that the sphere placed on the axis of the direction of incident neutron is a 'detector' used in our study to estimate the maximal dose. But it was not used at all for the calculation of the conversion coefficients.

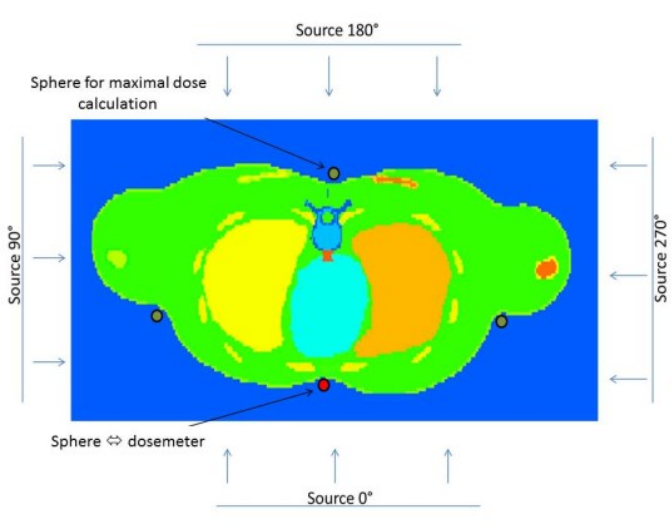

Figure 2. Illustration of the different configurations of irradiation for the anthropomorphic phantoms.

\section{Comparison to ICRP 116 data}

In order to compare our results obtained with real anatomy phantom with those obtained with a reference standard phantom, a comparison to the conversion coefficients from the ICRP report $n^{\circ} 116$ was performed [6]. It is not possible to do a direct comparison since the conversion coefficients calculated in this report the absorbed dose per fluence for a given organ, whereas the conversion coefficients calculated in our study is defined as the absorbed dose for a given organ per neutron kerma in tissue at NAD position on the trunk. However, the ratio of the conversion coefficients from ICRP for the AP incidence divided by ones obtained for the PA incidence should be similar to the ratio of the doses at the organ for the AP irradiation divided by the PA irradiations obtained in our MCNP calculations. Such AP/PA ratio are shown in Figures 3, 4, 5 and 6 (one figure per a given organ).

In the paper describing the construction of the M $1 \mathrm{i}$ phantoms (i from A to I), a comparison was performed between the ICRP phantom and the M 1C phantom for the absorbed organ doses calculated with the MCNPX Monte Carlo code for a $0.5 \mathrm{MeV}$ photon beam in AP irradiation geometry [3]. This study already showed that, even for mono-energetic photons, the ratio could differ not in a negligible way: $-10 \%$ for the prostate, $+1 \%$ for the liver, $-15 \%$ for the stomach wall for instance. The differences noted are easily understandable: the shape and the position of the organs inside the body are far different even if the total weight quite similar. Such an observation is all the more amplified with neutrons considering the higher attenuation with light nuclei composing tissue. For the AP/PA ratio, if ICRP phantom data are in good agreement for lung with the MIC data, significant difference can be observed for other organs reaching a 


\section{SAMPLE ET AL}

factor of two for the stomach wall. But looking at the position of the organ inside the different phantoms (cf. Figure 7 giving the transverse slices of the phantoms), one can notice that the stomach is located close to the center of the body for the M 1C phantoms whereas it is situated very closed to the front face of the body for the ICRP phantom. Therefore, even if mass body index are very close between the two considered phantoms, the different organ positions in the body explain the observed difference of for the reported ratio of coefficients. Moreover the difference reaches a maximum at $1 \mathrm{MeV}$, that is about the mean energy of the fast neutron peak in criticality accident, keeping in mind that most of the dose is provided by this fast neutron component. This result highlights the necessity to use for calculation, in the case of an irradiation with a neutron component, phantom based on the real morphology of the exposed individuals. In case of an acute exposure, the dose estimation has to be as accurate as possible, and one easily understand that a factor of two is not acceptable when considering deterministic effects. The use of standard phantom does not seems appropriate in that case. Considering individual with mass body index very different from the standard phantom, larger difference are expected as shown in Figures 4 to 6.

The ratio of the conversion coefficients given by ICRP for the RLAT irradiation incidence divided by the LLAT irradiation incidence is plotted for different organs (liver, both lungs, colon, stomach wall, bladder wall and both testes). Similar ratio was calculated for three other phantoms (MIA, MIC and one M1I). All these results are presented at the Figures 8, 9, 10 and 11. There is around a factor two between the RLAT/LLAT ratios for ICRP phantom than for the M1A phantom for the liver. Again, the differences of the positions and shapes of the organ could explain such difference.

Differences could also be explained by another reason. For instance, for the dose inside the stomach wall, the ICRP data estimates the dose performing a kerma approximation which is not the case in our study. Indeed, the fact that organ is a hollow organ might lead to a huge gradient of dose and large dose step at wall surface which could not be correctly taken into account using such approximation.

Focusing on the behavior of the conversion coefficients as a function of the corpulence (for M1A to M1I phantoms) is consistent altogether: the fattest the victim is, the closest the ratio reaches the value 1 . The behavior around $1 \mathrm{MeV}$ could be explained by the neutron cross section on nitrogen inside the body.

To conclude, such comparison enhances the large impact of the morphology (corpulence but also shape and position of the organs) on the conversion coefficients, all the more for the assessments of neutron doses.

\section{RESULTS AND DISCUSSION}

\section{Conversion coefficients}

The Figure 12 represents the ratio of the dose at one specific organ divided by the neutron kerma in tissue calculated at the dosemeter location, for the M1C phantom for a neutron source for an incidence of $0^{\circ}$. The whole data are also given in table 1 .

\section{Dose to the organs}

The proportions of the dose induced by the neutrons or the photons for neutrons of $1 \mathrm{MeV}$ as a function of the organs are particularly relevant. This incident neutron energy of $1 \mathrm{MeV}$ corresponds, for all organs, to the transition between a major contribution of the secondary charged particles or recoil nuclei from neutrons interaction $(\mathrm{E}>1 \mathrm{MeV})$ and a major contribution of the photons mainly from capture reaction on hydrogen $(\mathrm{E}<1 \mathrm{MeV})$ as it is illustrated in the Figure 13. If we compare the left lung and the prostate which is more deeply situated in the body than the lung for an incidence of $0^{\circ}$, the percentage of the dose due to charged particles or recoil nuclei divided by the total dose is about $75 \%$ for the lung and only $46 \%$ for the prostate. This effect can be easily understood by the fact that the neutrons are thermalized in tissue depth favoring capture reaction and that secondary particle of capture reaction (mainly gamma of $2.2 \mathrm{MeV}$ ) deposited energy on a longer range than charged particles or recoil nuclei from reaction with fast neutrons. Therefore, the proportion of dose due to secondary gamma to the total dose from neutron increases with thickness of tissue. Table 2 gives the proportion of the dose as a function of the secondary particle type for the different neutron energies (for the $\mathrm{M} 1 \mathrm{C}$ phantom for an incidence of $0^{\circ}$ ).

Calculating these conversion coefficients for the different organs can be very useful in case of criticality accident in order to estimate very quickly which organs will receive the maximum doses. For an incidence of $0^{\circ}$, the organ that received the maximum dose is the liver, followed by the lungs and the heart (cf. 
Figure 14, and associated Table 3). The prostate receives a very small dose in comparison to the dose received by all the others organs.

\section{Influence of the irradiation angle}

A study concerning the incident angle of the neutron field was also performed. A first conclusion is that whatever the studied organ is, the conversion coefficients are maximum for the irradiation incidence of $180^{\circ}$. This can be shown for instance in the Figure 15 giving the ratios of the conversion coefficient for the left lung in the M $1 \mathrm{~A}$ phantom $\left(90^{\circ} / 0^{\circ} ; 180^{\circ} / 0^{\circ}\right.$, and $270^{\circ} / 0^{\circ}$ ) as a function of the neutron energy. Such result which is valid even for organs that are not situated deeply inside the body such as the left lung can be explained by the Figure 16: the ratio PA/AP of the neutron kerma given by the dosemeter for the M1A phantom is shown and compared to the ratio of the dose at the organs for the same phantom and for three different organs (liver, left lung and heart). We can see that, on one hand, the ratio PA/AP is deeply impacted for the dosemeters (more than 3 orders of magnitude between 1e-9 to $1 \mathrm{MeV}$ ) and less affected for higher neutron energies. This is an expected results: neutrons are scattered and slowed down in the tissue of the body before interacting in the dosemeter worn at the front. On the other hand, the PA/AP ratio for the doses at the organs is less affected. The figure 16 shows that there is, at maximum, a decrease of $-60 \%$ at $1 \mathrm{MeV}$ for the dose at the liver. That explains the results presented in Figure 15, even for an organ which is not situated deeply inside the body, such as the left lung.

Concerning the lateral incidences, the conversion coefficients vary as a function of the position of the organ in the body. For instance, if we consider the left lung, for the M1A phantom, we notice that the conversion coefficients are 100 times higher for an irradiation coming from the right side than for the left side.

\section{Influence of the corpulence of the phantom}

To investigate the influence of the corpulence, we studied four different phantoms: a very thin one (M1A), a healthy person (the reference M1C, BMI = 23.3) and two more or less overweighed ones (M 1E and M1I). The Figure 17 gives the ratios of the total dose at the organ for the M1A phantom divided by the total dose at the organ for the M1I phantom, for different organs, and as a function of the neutron energy. For thermal and epithermal neutrons, this ratio varies from 1 to a bit more than 3 for all organs presented here. Such ratio could reach a value of more than 8 for colon and liver at $1 \mathrm{MeV}$, and decrease for higher neutron energies. These data demonstrate the need to take into account the morphology of exposed persons to estimate the organ doses. For a same dose at the entrance, the prognostic could be very different for different individuals and therefore the medical treatment.

The difference in terms of dose and then of conversion coefficients, are mainly due to the thermalization of the fast neutrons (which implies an important dose) in the external layers of the skin. The corpulence of the victim must also be taken into account because there is a considerable influence on the dose to the organs.

\section{CONCLUSIONS}

The calculations presented in this paper permit to have a first database of conversion coefficients for neutron radiations for four incidences of the radiation field and three different mass body indexes of the victim (one "standard" and the two extremes in terms of weight). Such database can then be used to estimate quickly doses at the different organs for all victims of a criticality accident. Such database will be implemented in a user friendly tool in order to be the most efficient as possible.

The comparison to ICRP data is a complete demonstration that not only the corpulence of the victim is important, but also the position of the organ inside the body. This result underlines the needs to develop the DIOMEDE collaborative web tool. The richer the data base will be, the easier it will be to find a phantom that best fits the victim's morphology and position of the organs to assess in a very fast way the dose at the organs and then to define the best therapeutic strategy. In the next step of this work, more realistic geometries have to be defined, based on the study of criticality accidents.

Moreover, an uncertainty evaluation will have to be performed, in order to evaluate the minimal number of phantoms and geometries that should be implemented in the database in order to achieve the uncertainty on dose requested $(50 \%$ after 24 hours and $25 \%$ after one week) and to cover the larger range of morphology.

All these conversion coefficients could then enriched the DIOMEDE web tool. This free available tool could be feed by anyone willing to participate to this initiative. This initiative has been endorsed by EURADOS WG10 and it is planned that, in the future, an evaluation committee formed by EURADOS members will be in charge of the validation of coefficients submitted to be implemented in the DIOMEDE tool.

This very consequent and collaborative work will make up for the fact in a long term that there is, up to now, no proposed solution to assess those organ doses in short delay with the uncertainties requested. The study presented in this paper is a first step showing that using a standard phantom may lead to huge over or underestimation of organ doses. Knowing that is 
already a key information when defining the medical treatment and these first conversion coefficients could be useful as a base for a first dosimetric information.

\section{REFERENCES}

1. International Atomic Energy Agency, Dosimetry for criticality accidents, A Manual, Technical Report Series No211

2. Hervé M.-L., Dosimétrie d'accident en champ mixte (neutrons, photons) utilisant la spectrométrie par résonance paramagnétique électronique (RPE), $\mathrm{PhD}$ thesis from University Paris XI, Faculté de médecine, Paris-Sud, 2006
3. Broggio D. et al., Construction of an extended library of adult male 3D models : rationale and results, Phys. Med. Biol. 56765 (2011)

4. Oak Ridge \& Los Alamos National Laboratory. RSICC computer code collection, Monte Carlo N-Particle transport code system including MCNP6.1, MCNP5-1.60, MCNPX2.701 and data libraries. CCC-810 (2013)

5. ICRP, 2009. Adult Reference Computational Phantoms. ICRP Publication 110. Ann. ICRP 39 (2).

6. ICRP, 2010. Conversion Coefficients for Radiological Protection Quantities for External Radiation Exposures. ICRP Publication 116, Ann. ICRP 40(2-5). 
Table 1. Conversion coefficients for the M1C phantom for a neutron source at $0^{\circ}$.

\begin{tabular}{ccccccc}
\hline \multirow{2}{*}{$\begin{array}{c}\text { Neutron } \\
\text { energy }(\mathbf{M e V})\end{array}$} & \multicolumn{5}{c}{ Conversion coefficients for M1C phantom, AP irradiation } \\
\cline { 2 - 7 } & Colon & R lung & Stomach & R Testis & Liver & Bladder \\
\hline $1 \mathrm{E}-09$ & $1.0 \mathrm{E}+09$ & $1.1 \mathrm{E}+09$ & $9.8 \mathrm{E}+08$ & $1.8 \mathrm{E}+09$ & $1.3 \mathrm{E}+09$ & $1.1 \mathrm{E}+09$ \\
$1 \mathrm{E}-08$ & $1.2 \mathrm{E}+09$ & $1.3 \mathrm{E}+09$ & $1.2 \mathrm{E}+09$ & $2.1 \mathrm{E}+09$ & $1.6 \mathrm{E}+09$ & $1.4 \mathrm{E}+09$ \\
$1 \mathrm{E}-07$ & $7.7 \mathrm{E}+08$ & $8.3 \mathrm{E}+08$ & $7.4 \mathrm{E}+08$ & $1.3 \mathrm{E}+09$ & $1.0 \mathrm{E}+09$ & $8.8 \mathrm{E}+08$ \\
$1 \mathrm{E}-06$ & $1.4 \mathrm{E}+08$ & $1.4 \mathrm{E}+08$ & $1.4 \mathrm{E}+08$ & $2.1 \mathrm{E}+08$ & $1.7 \mathrm{E}+08$ & $1.6 \mathrm{E}+08$ \\
$1 \mathrm{E}-05$ & $1.5 \mathrm{E}+07$ & $1.6 \mathrm{E}+07$ & $1.5 \mathrm{E}+07$ & $2.3 \mathrm{E}+07$ & $1.9 \mathrm{E}+07$ & $1.7 \mathrm{E}+07$ \\
$1 \mathrm{E}-04$ & $1.5 \mathrm{E}+06$ & $1.5 \mathrm{E}+06$ & $1.5 \mathrm{E}+06$ & $2.1 \mathrm{E}+06$ & $1.9 \mathrm{E}+06$ & $1.7 \mathrm{E}+06$ \\
$1 \mathrm{E}-03$ & $2.2 \mathrm{E}+04$ & $2.2 \mathrm{E}+04$ & $2.2 \mathrm{E}+04$ & $2.9 \mathrm{E}+04$ & $2.7 \mathrm{E}+04$ & $2.6 \mathrm{E}+04$ \\
$1 \mathrm{E}-02$ & $2.4 \mathrm{E}+02$ & $2.3 \mathrm{E}+02$ & $2.5 \mathrm{E}+02$ & $3.2 \mathrm{E}+02$ & $2.9 \mathrm{E}+02$ & $2.8 \mathrm{E}+02$ \\
$1 \mathrm{E}-01$ & $3.9 \mathrm{E}+00$ & $4.0 \mathrm{E}+00$ & $4.0 \mathrm{E}+00$ & $7.5 \mathrm{E}+00$ & $4.9 \mathrm{E}+00$ & $4.4 \mathrm{E}+00$ \\
1 & $2.3 \mathrm{E}-01$ & $3.4 \mathrm{E}-01$ & $1.8 \mathrm{E}-01$ & $7.7 \mathrm{E}-01$ & $3.4 \mathrm{E}-01$ & $2.4 \mathrm{E}-01$ \\
5 & $1.4 \mathrm{E}-01$ & $1.6 \mathrm{E}-01$ & $1.2 \mathrm{E}-01$ & $2.1 \mathrm{E}-01$ & $1.6 \mathrm{E}-01$ & $1.4 \mathrm{E}-01$ \\
10 & $8.0 \mathrm{E}-02$ & $8.7 \mathrm{E}-02$ & $7.4 \mathrm{E}-02$ & $1.1 \mathrm{E}-01$ & $8.7 \mathrm{E}-02$ & $8.0 \mathrm{E}-02$ \\
20 & $4.9 \mathrm{E}-02$ & $5.1 \mathrm{E}-02$ & $4.6 \mathrm{E}-02$ & $5.9 \mathrm{E}-02$ & $5.1 \mathrm{E}-02$ & $4.8 \mathrm{E}-02$ \\
\hline
\end{tabular}




\section{Liver}

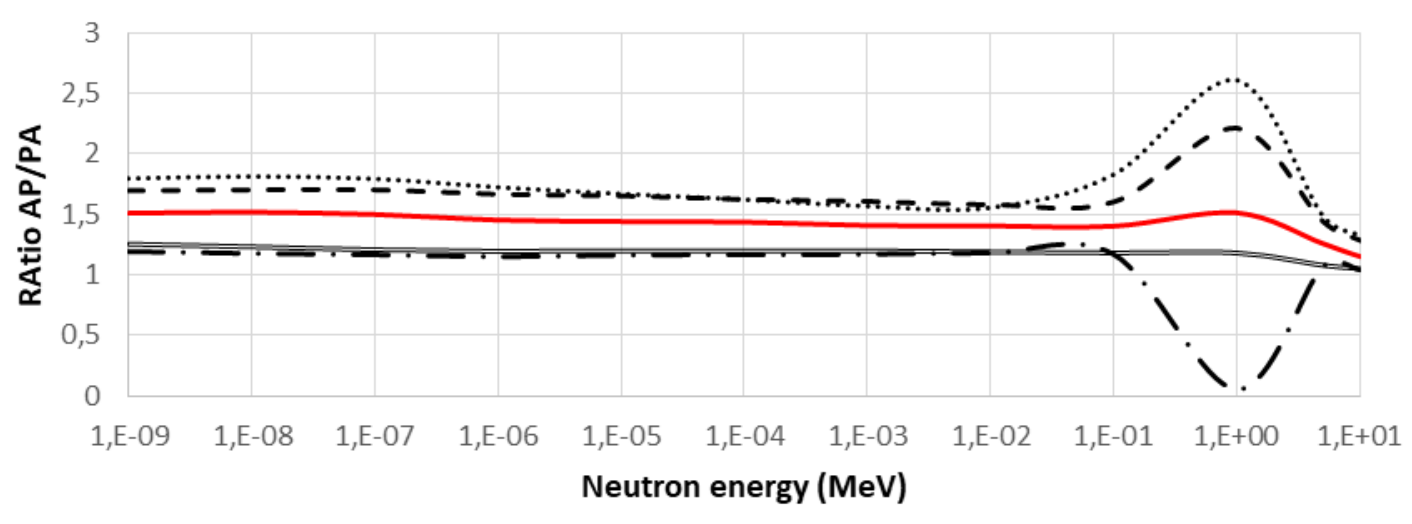

- ICRP $116 \quad$......... M1A phantom - - - M1C phantom

M1E phantom - - M1I phantom

Figure 3. AP/PA ratio of the conversion coefficients for the ICRP report (red curves) and AP/PA ratio of the organ doses for the liver estimated in our calculations with 4 different phantoms ( 4 black curves).

\section{Lung}

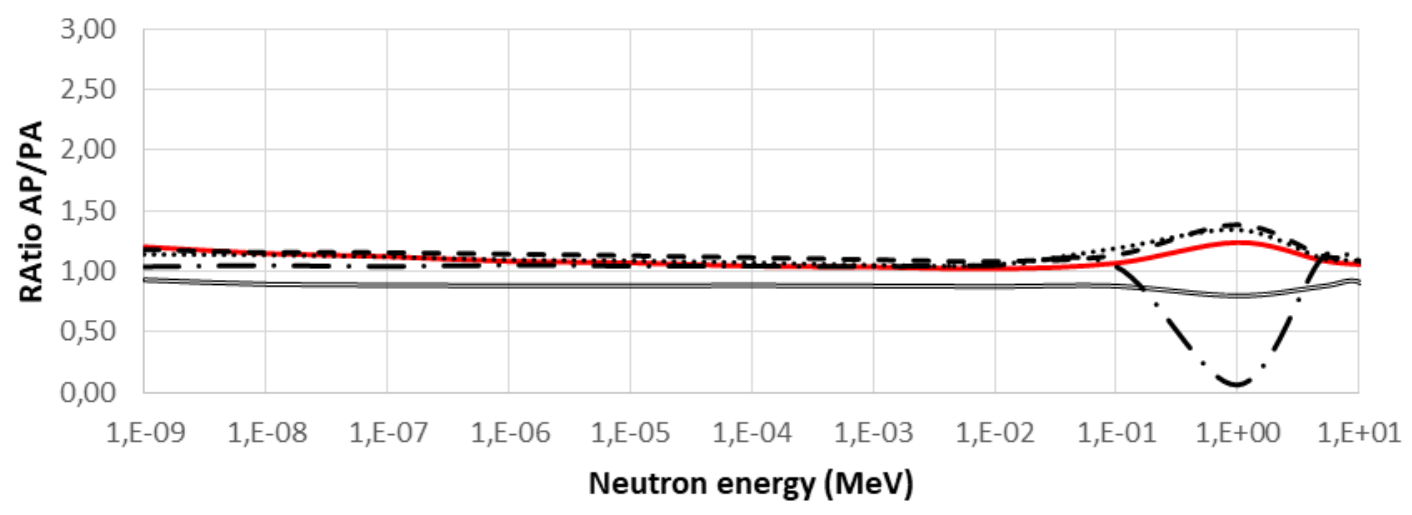

ICRP $116 \quad$-........ M1A phantom - - - M1C phantom

M1E phantom - - M1I phantom

Figure 4. AP/P Aratio of the conversion coefficients for the ICRP report (red curves) and AP/PA ratio of the organ doses for the lung estimated in our calculations with 4 different phantoms (4 black curves). 


\section{Bladder}
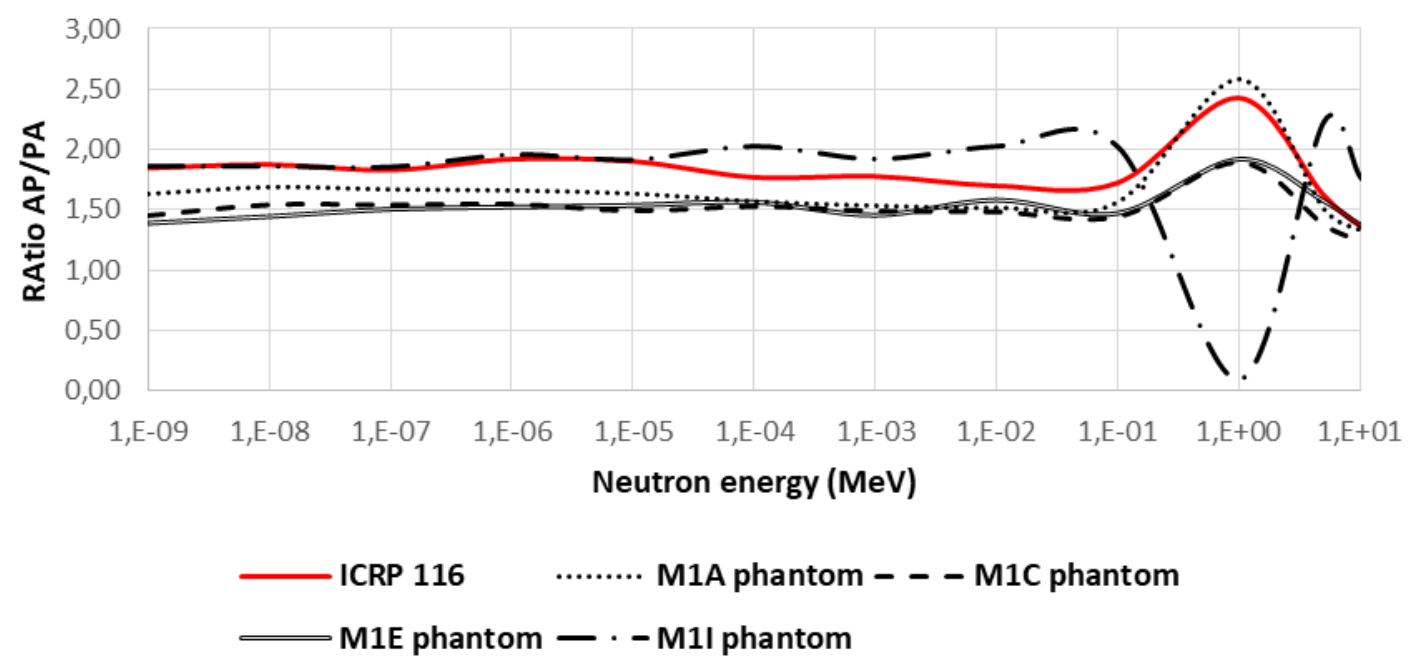

Figure 5. AP/PAratio of the conversion coefficients for the ICRP report (red curves) and AP/PA ratio of the organ doses for the bladder estimated in our calculations with 4 different phantoms ( 4 black curves).

\section{Stomach}

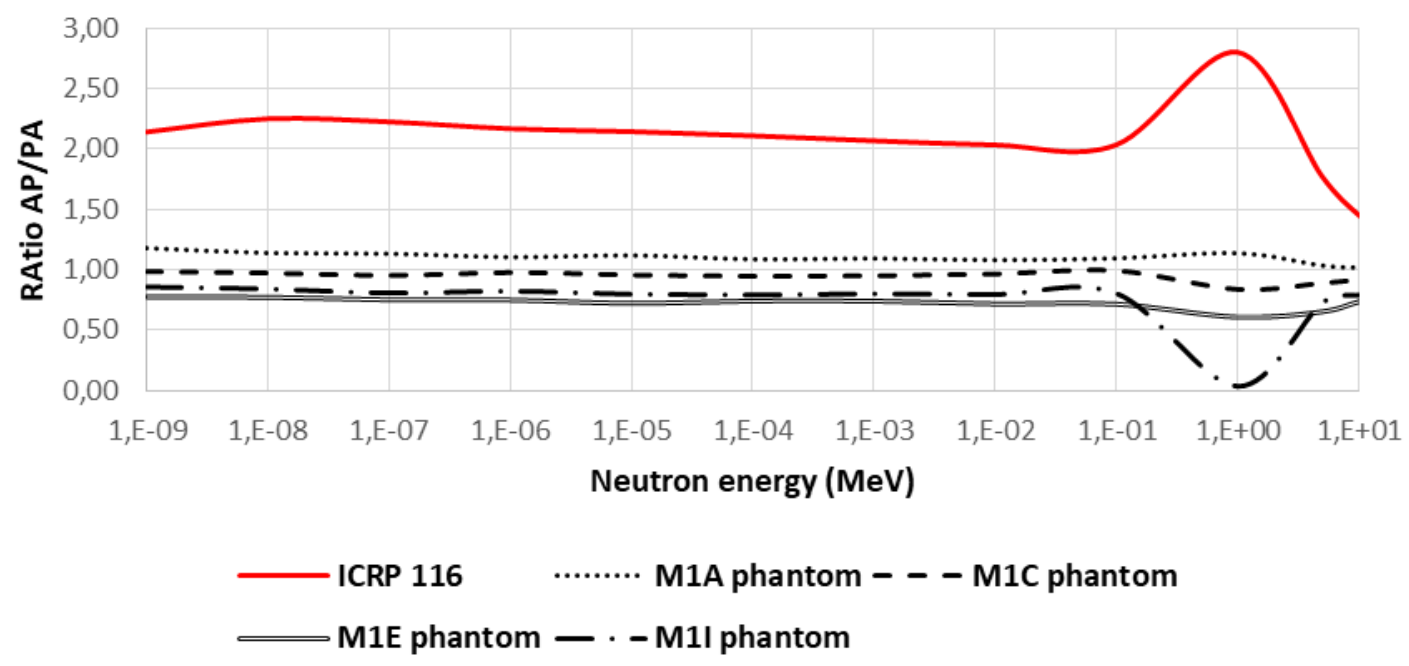

Figure 6. AP/P A ratio of the conversion coefficients for the ICRP report (red curves) and AP/PA ratio of the organ doses for the stomach estimated in our calculations with 4 different phantoms (4 black curves). 

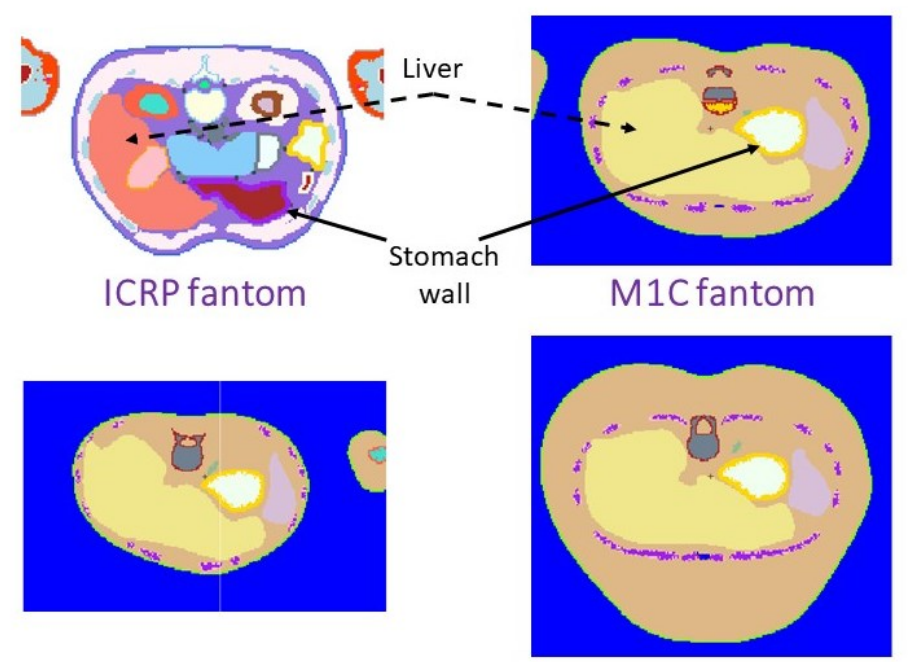

M1A fantom

M1E fantom

Figure 7. Transverse slice through the different phantoms. 


\section{ICRP fantom}

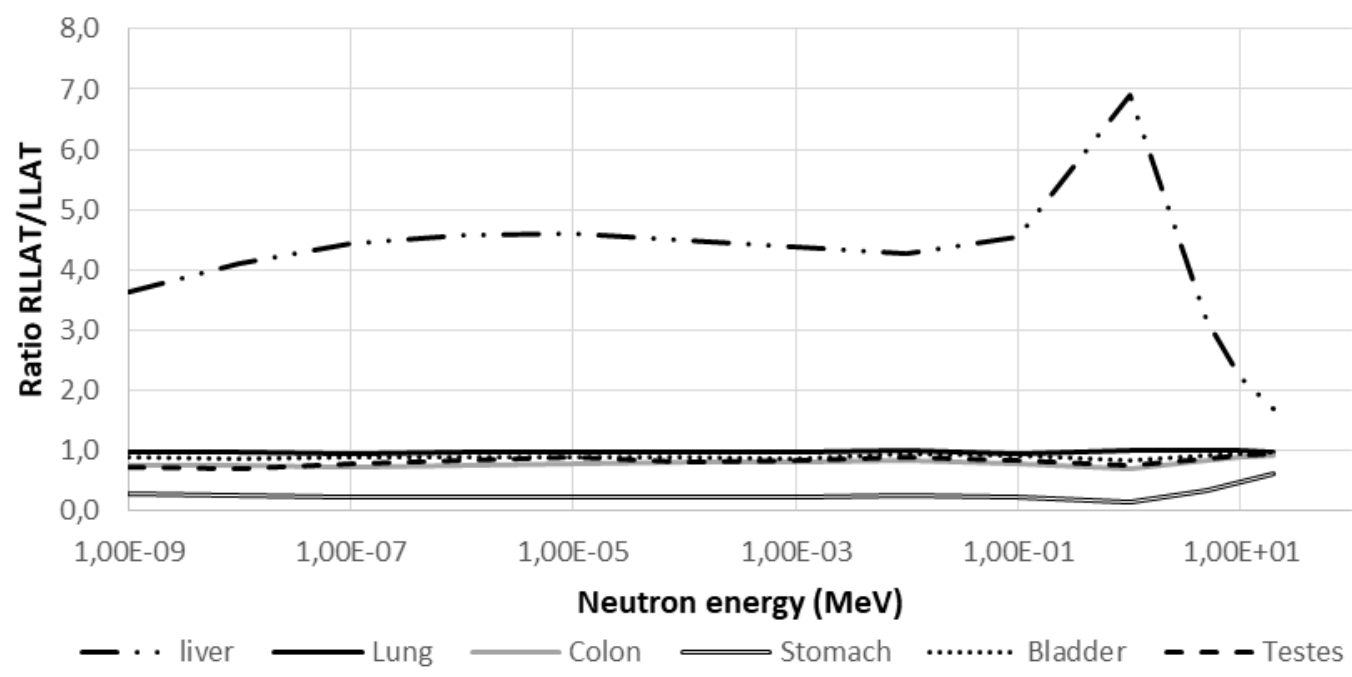

Figure 8. RLAT/LLAT ratios of the conversion coefficients as a function of neutron energy, for different organs, for the ICRP phantom.

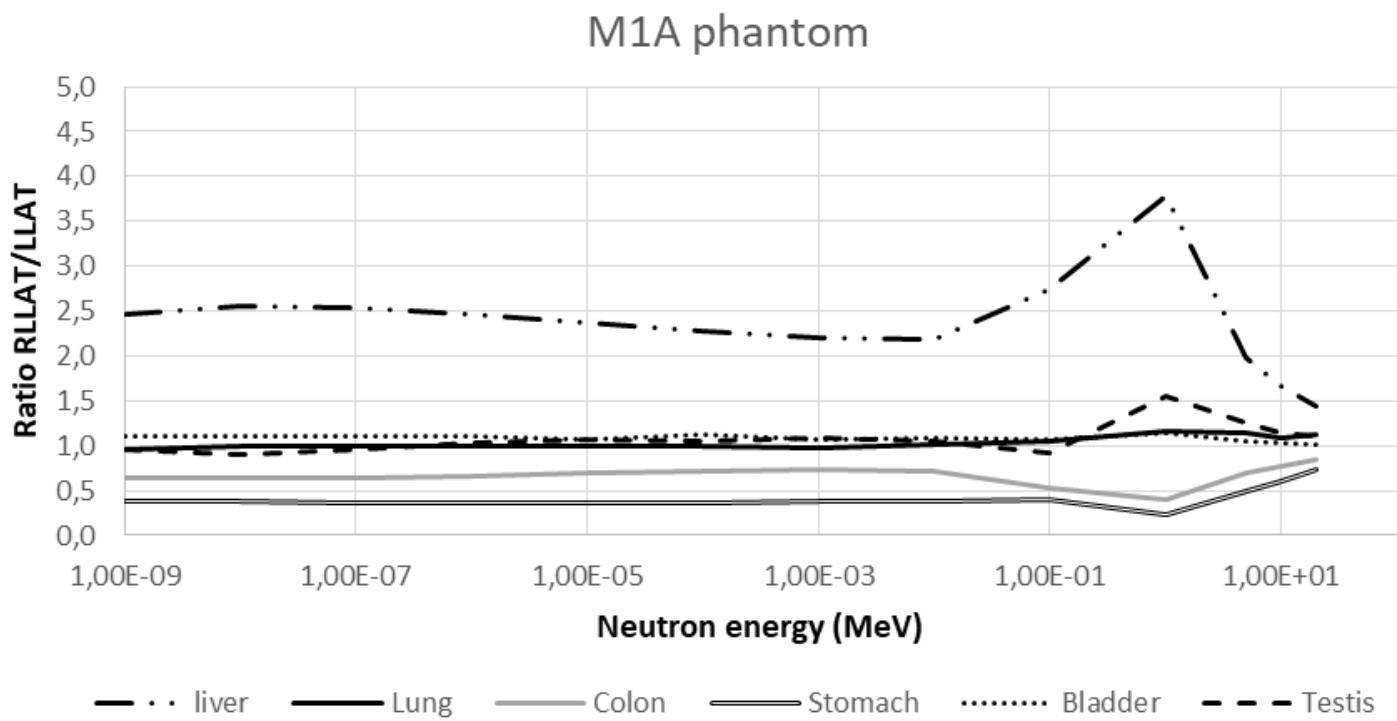

Figure 9. RLAT/LLAT ratios of the conversion coefficients as a function of neutron energy, for different organs, for the M1A phantom. 


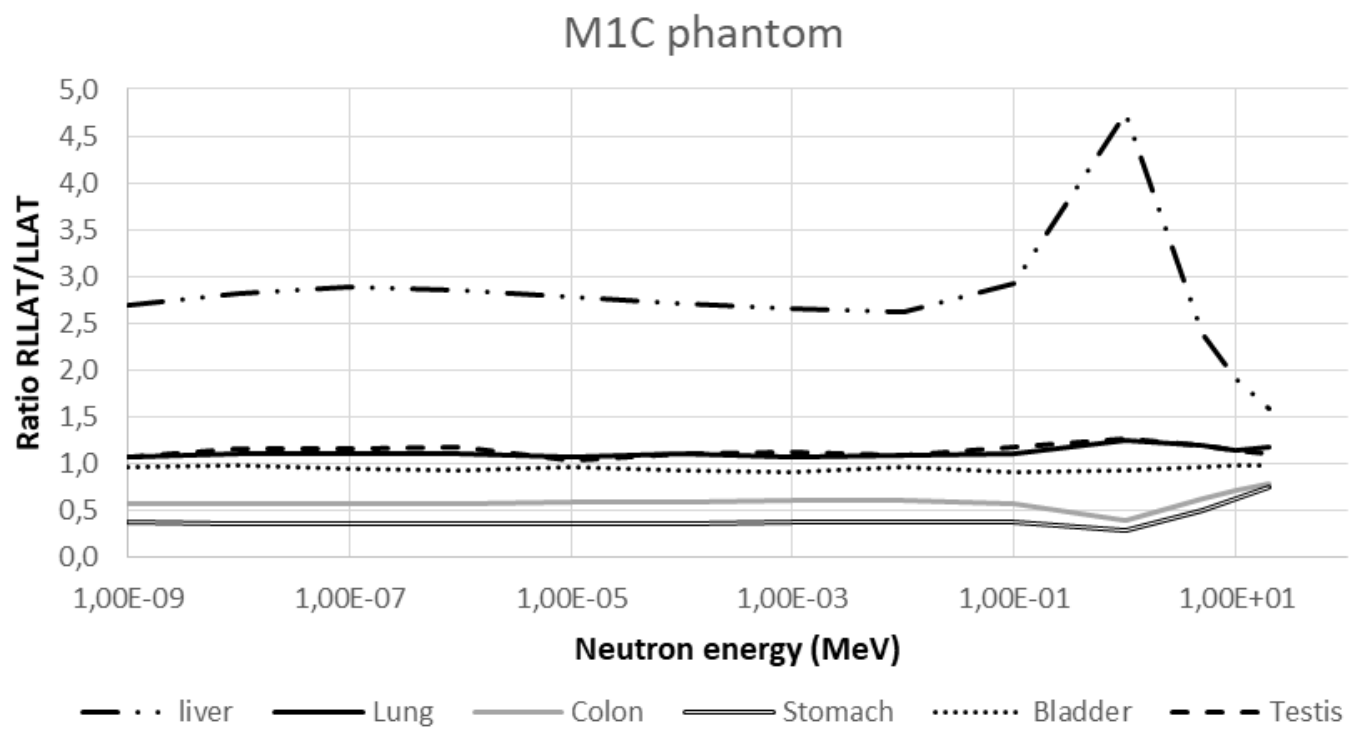

Figure 10. RLAT/LLAT ratios of the conversion coefficients as a function of neutron energy, for different organs, for the M1C phantom.

\section{M1I phantom}

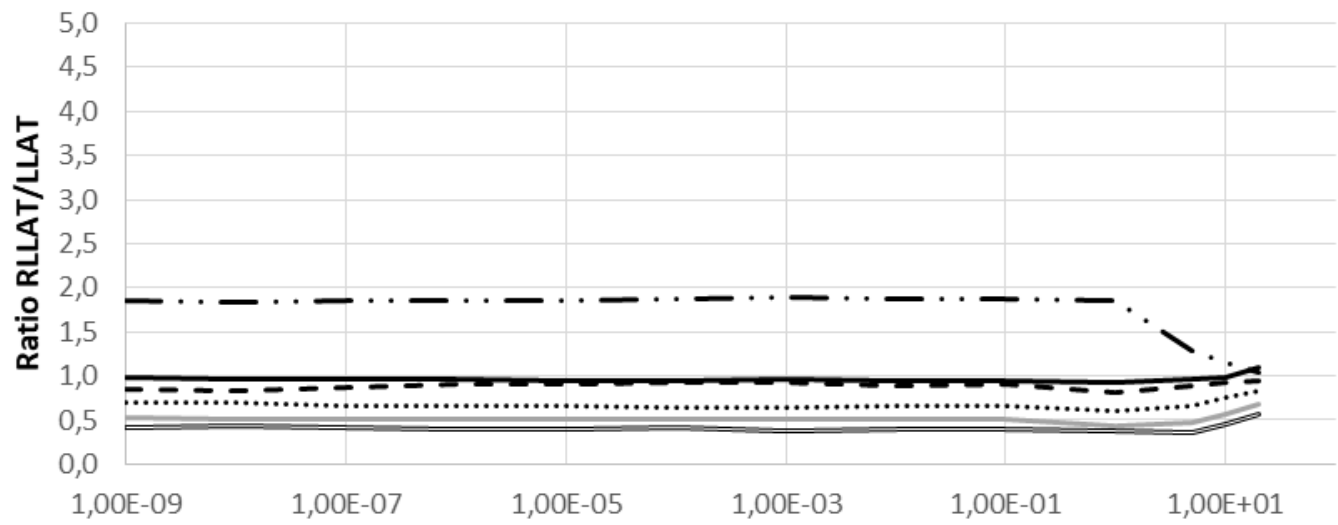

Neutron energy (MeV)

—. . liver — Lung $\longrightarrow$ Colon $\rightleftharpoons$ Stomach $\quad$......... Bladder $\quad$ - - - Testis

Figure 11. RLAT/LLAT ratios of the conversion coefficients as a function of neutron energy, for different organs, for the M1I phantom. 
SHORT TITILE 


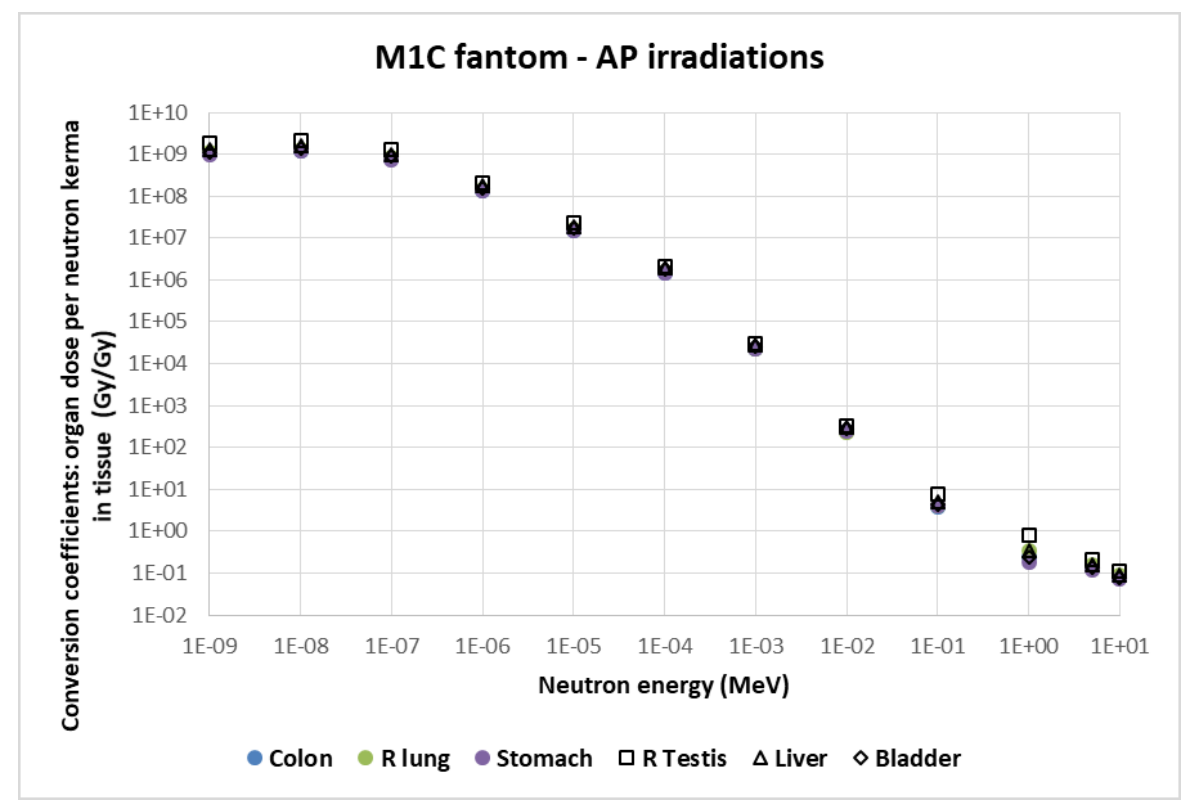

Figure 12. Conversion coefficients for the M1C phantom for a neutron source at $0^{\circ}$.

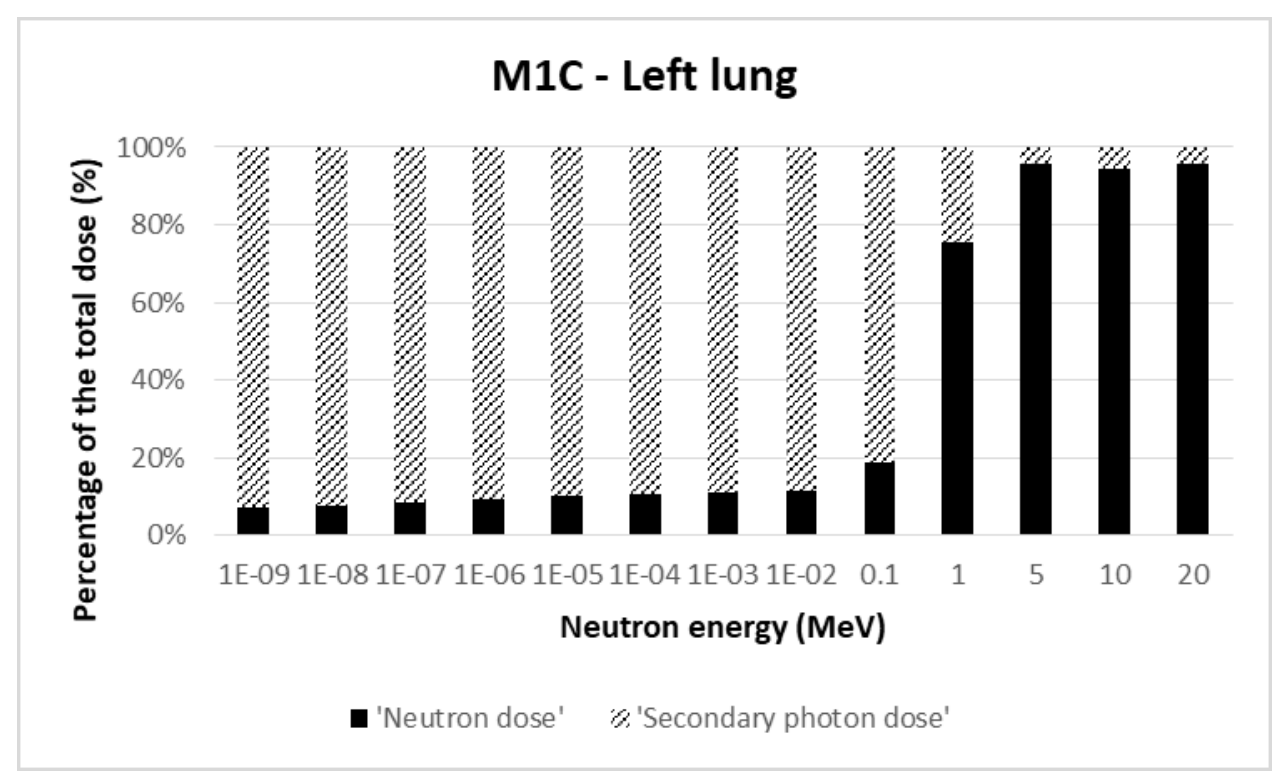

Figure 13. Contribution of the dose as a function of types of secondary particles, for theleft lung, for thephantom M1C with an incidence of $0^{\circ}$. 
Table 2. Percentage of the dose induced by neutrons only on the total dose, for the M1C phantom and for an incidence of $0^{\circ}(\%)$.

\begin{tabular}{ccc}
\hline & $\begin{array}{c}\text { Percentage of the total dose } \\
\text { induced by ne utrons only }(\%)\end{array}$ \\
\hline $\begin{array}{c}\text { Neutron } \\
\text { energy } \\
\text { (Me V) }\end{array}$ & Prostate & $\begin{array}{c}\text { Left } \\
\text { Lung }\end{array}$ \\
\hline 1E-09 & 4 & 7 \\
$1 \mathrm{E}-08$ & 4 & 8 \\
$1 \mathrm{E}-07$ & 4 & 9 \\
$1 \mathrm{E}-06$ & 5 & 9 \\
$1 \mathrm{E}-05$ & 5 & 10 \\
$1 \mathrm{E}-04$ & 6 & 11 \\
$1 \mathrm{E}-03$ & 6 & 11 \\
$1 \mathrm{E}-02$ & 7 & 12 \\
0,1 & 8 & 19 \\
1 & 48 & 75 \\
5 & 92 & 96 \\
10 & 92 & 94 \\
20 & 94 & 96 \\
\hline
\end{tabular}

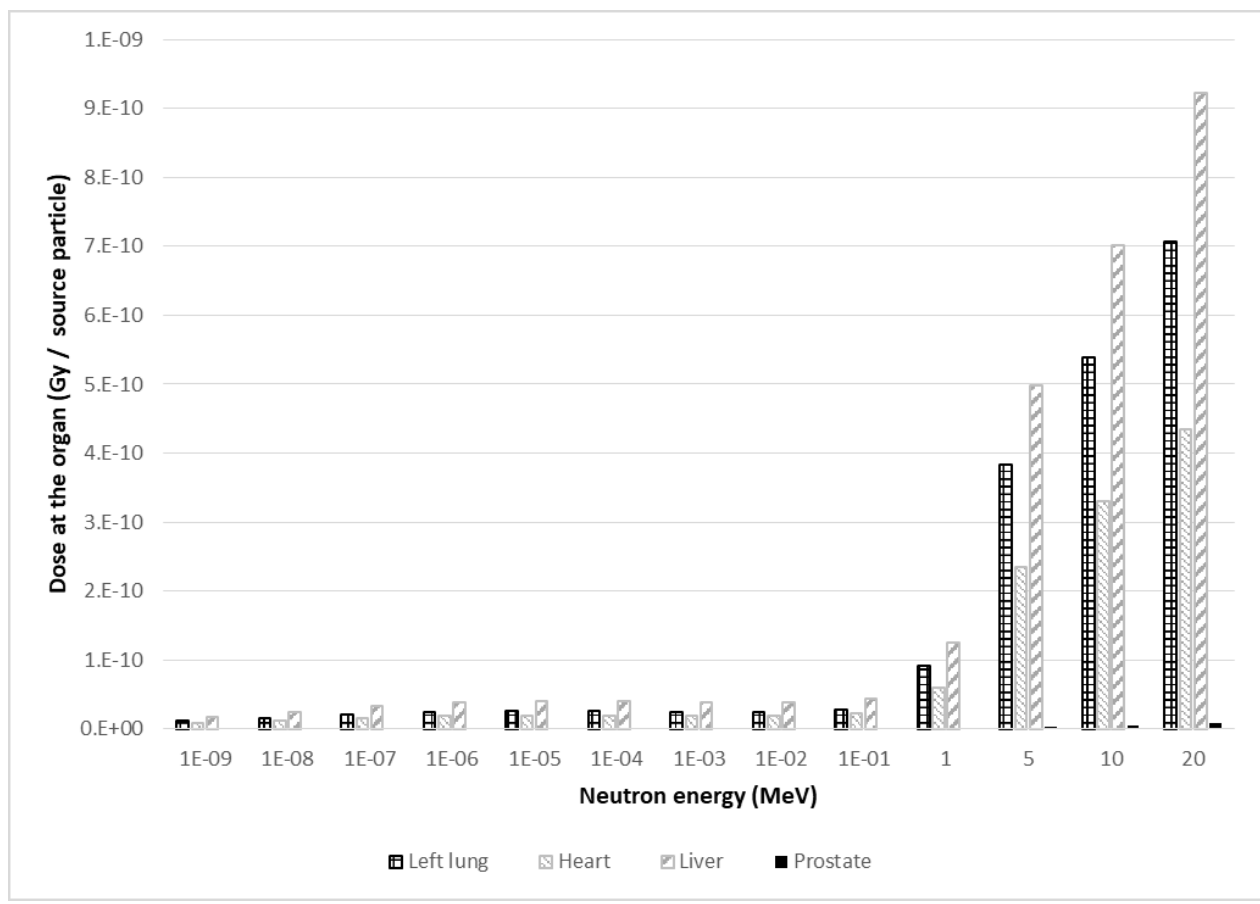

Figure 14. Dose for four different organs for the M1C phantom with an incidence of $0^{\circ}$. 
Table 3. Dose at the organ (Gy/source particles) for the M1C phantom and for a neutron source at $0^{\circ}$.

\begin{tabular}{ccccc}
\multirow{2}{*}{$\begin{array}{c}\text { Neutron energy } \\
(\text { Me V) }\end{array}$} & \multicolumn{4}{c}{$\begin{array}{c}\text { Dose at the organ (Gy/source particle) } \\
\text { AP irradiation, M1C phantom }\end{array}$} \\
\cline { 2 - 5 } & Left lung & Heart & Liver & Prostate \\
\hline $1 \mathrm{E}-09$ & $1.1 \mathrm{E}-11$ & $8.3 \mathrm{E}-12$ & $1.7 \mathrm{E}-11$ & $1.4 \mathrm{E}-13$ \\
$1 \mathrm{E}-08$ & $1.6 \mathrm{E}-11$ & $1.1 \mathrm{E}-11$ & $2.4 \mathrm{E}-11$ & $1.8 \mathrm{E}-13$ \\
$1 \mathrm{E}-07$ & $2.1 \mathrm{E}-11$ & $1.6 \mathrm{E}-11$ & $3.3 \mathrm{E}-11$ & $2.4 \mathrm{E}-13$ \\
$1 \mathrm{E}-06$ & $2.5 \mathrm{E}-11$ & $1.9 \mathrm{E}-11$ & $3.8 \mathrm{E}-11$ & $2.9 \mathrm{E}-13$ \\
$1 \mathrm{E}-05$ & $2.6 \mathrm{E}-11$ & $2.0 \mathrm{E}-11$ & $4.0 \mathrm{E}-11$ & $3.1 \mathrm{E}-13$ \\
$1 \mathrm{E}-04$ & $2.6 \mathrm{E}-11$ & $2.0 \mathrm{E}-11$ & $4.0 \mathrm{E}-11$ & $3.1 \mathrm{E}-13$ \\
$1 \mathrm{E}-03$ & $2.5 \mathrm{E}-11$ & $2.0 \mathrm{E}-11$ & $3.9 \mathrm{E}-11$ & $3.1 \mathrm{E}-13$ \\
$1 \mathrm{E}-02$ & $2.5 \mathrm{E}-11$ & $2.0 \mathrm{E}-11$ & $3.9 \mathrm{E}-11$ & $3.2 \mathrm{E}-13$ \\
$1 \mathrm{E}-01$ & $2.9 \mathrm{E}-11$ & $2.2 \mathrm{E}-11$ & $4.4 \mathrm{E}-11$ & $3.6 \mathrm{E}-13$ \\
1 & $9.1 \mathrm{E}-11$ & $5.9 \mathrm{E}-11$ & $1.3 \mathrm{E}-10$ & $7.0 \mathrm{E}-13$ \\
5 & $3.8 \mathrm{E}-10$ & $2.3 \mathrm{E}-10$ & $5.0 \mathrm{E}-10$ & $3.9 \mathrm{E}-12$ \\
10 & $5.4 \mathrm{E}-10$ & $3.3 \mathrm{E}-10$ & $7.0 \mathrm{E}-10$ & $6.0 \mathrm{E}-12$ \\
20 & $7.1 \mathrm{E}-10$ & $4.3 \mathrm{E}-10$ & $9.2 \mathrm{E}-10$ & $8.4 \mathrm{E}-12$ \\
\hline
\end{tabular}

\section{Left lung}

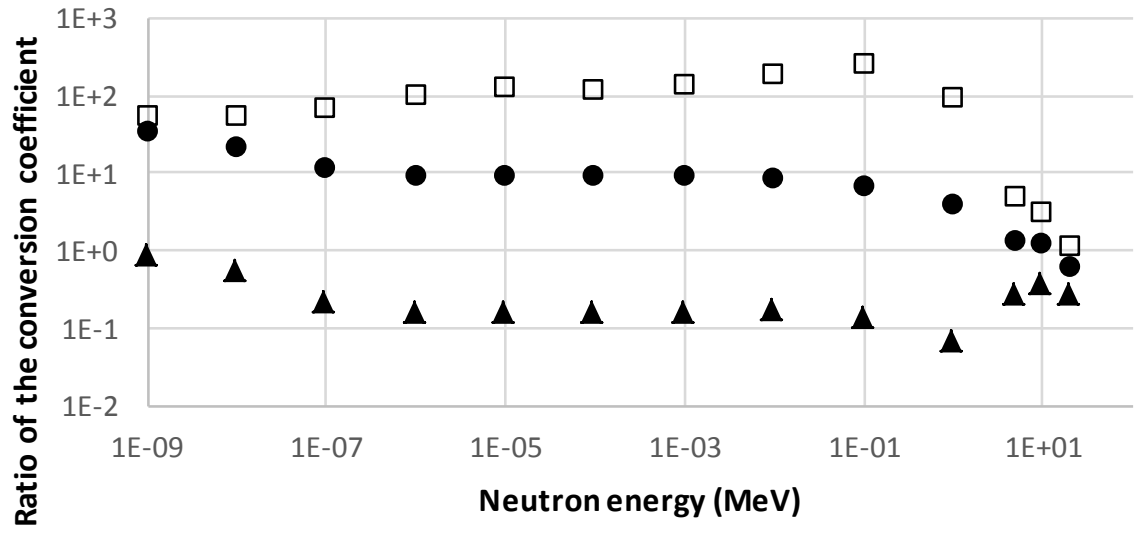

$\Delta 90^{\circ} / 0^{\circ} \square 180^{\circ} / 0^{\circ} \bigcirc 270^{\circ} / 0^{\circ}$

Figure 15. Ratio of the coefficients for the $90^{\circ}$ or $180^{\circ}$ or $270^{\circ}$ of incidence divided by the $0^{\circ}$ one, for the M1A phantom for the left lung. 


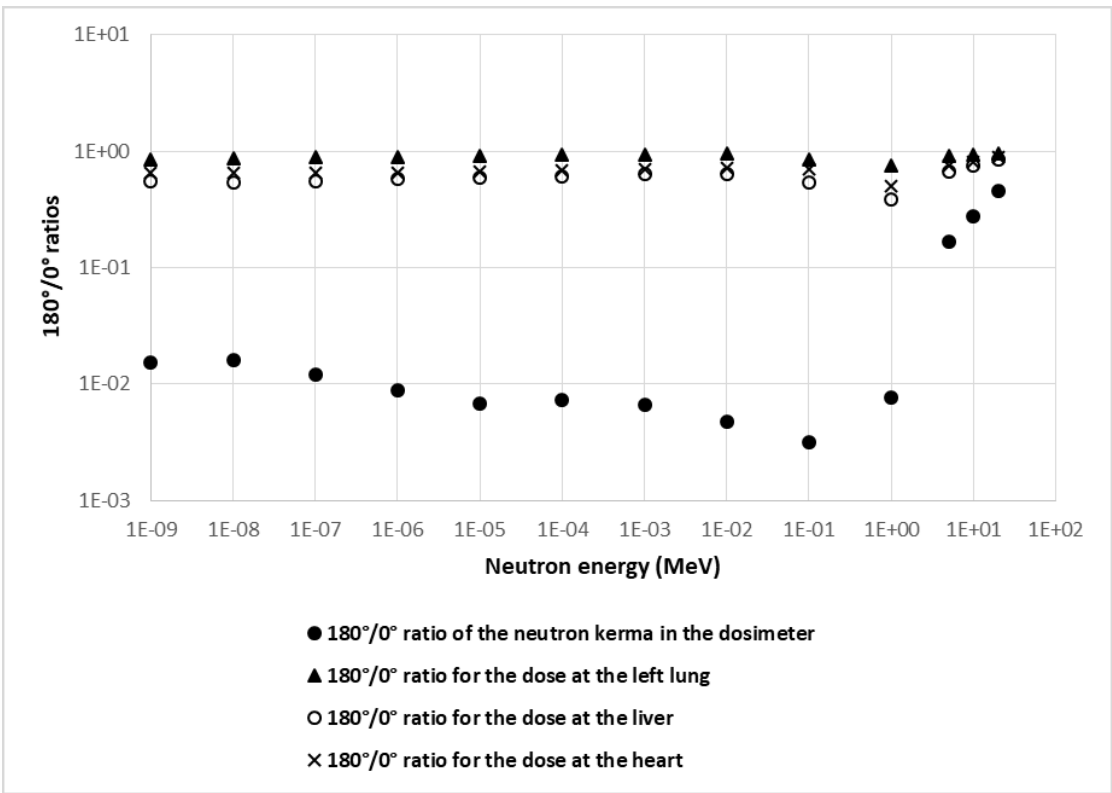

Figure 16. PA/AP ratios of the neutron kerma in tissue and for different doses at the organs, for the M1 A phantom.

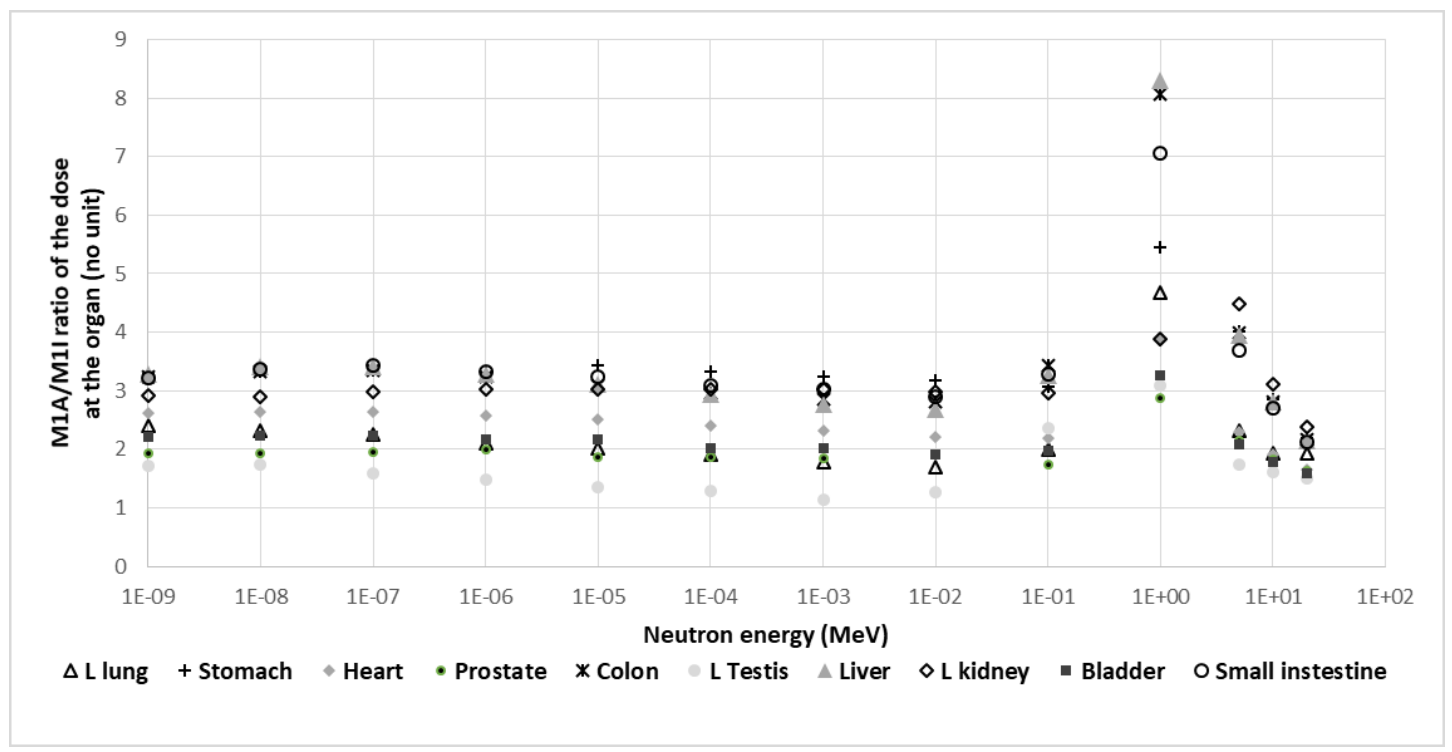

Figure 17. Ratio of the dose at the organ for the M1A phantom divided by the dose at the organ for the M1I phantom, for different organs, and as a function of the neutron energy. 